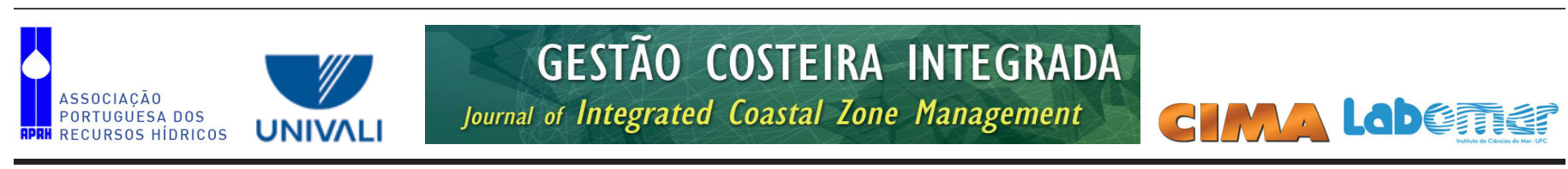

http://www.aprh.pt/rgci/pdf/rgci-356_Oliveira.pdf | DOI:10.5894/rgci356

\title{
Expansão Portuária, Desenvolvimento Municipal e Alterações Ambientais no Brasil: Desafios para a gestão costeira *
}

\author{
Port Expansion, Municipal Development and Environmental Changes in \\ Brazil: Challenges for Coastal Management
}

\author{
D. S. Oliveira ${ }^{\circledR, 1}$, M. V. D. R. Domingues ${ }^{1}$, M. L. Asmus ${ }^{1}$, P. R. Abdallah ${ }^{1}$
}

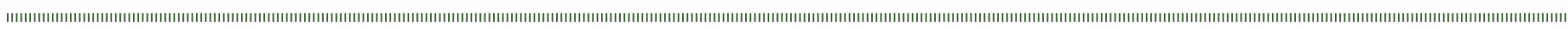

\section{RESUMO}

Os municípios costeiros apresentam uma gama de conflitos de uso em seu território, e a presença de um porto de considerável importancia aumenta a complexidade de suas relaçóes. Para que se tenha um melhor entendimento dos desafios da gestão costeira tornase necessário uma visão sistêmica da evoluçáo do processo do desenvolvimento e suas conseqüências na urbe. O planejamento territorial e de seus recursos nestes municípios costeiros não é uma tarefa nada fácil. Por um lado, existem as pressôes de âmbito local, como invasões de áreas de preservação ambiental, déficit crescente na infraestrutura, desemprego e subemprego causados pela instabilidade econômica nacional e mundial. Por outro lado, há pressóes político-econômicas da esfera estadual e federal induzidas pelos macroprojetos de desenvolvimento. O objetivo deste artigo é correlacionar o crescimento portuário com o desenvolvimento municipal e com o passivo socioambiental por ele causado, evidenciando novas demandas de gestão costeira. O município de Rio Grande (RS, Brasil) foi utilizado como estudo de caso em uma análise sistêmica desse processo. As fases de crescimento portuário foram identificadas a partir dos dados de movimentação de carga e correlacionadas com os indicadores de desenvolvimento. A alteração físico natural foi avaliada a partir de um SIG da expansão urbana, comparando os anos de 1975 e 2009. As melhorias em infraestrutura urbana foram consolidadas apenas nos períodos em que estiveram presentes os investimentos federais, caracterizados como ciclos de crescimento exógeno. O processo gerou alteração ambiental, mais significativa nas unidades físico ambientais do tipo cristas praiais litorâneas com campos litorâneos. A análise do processo pela ótica sistêmica evidencia que os atores locais não estão capacitados para absorver os passivos socioambientais gerados pela implantação de macroprojetos. Este fato é agravado pela forte pressão exercida pelo setor privado, industrial e imobiliário, contribuindo para a desarticulação das políticas e instrumentos de gestão. Há em municípios, como no caso estudado, a alternativa entre o crescimento econômico rápido com constrangimentos para a população e perda da sustentabilidade ambiental, ou um crescimento balizado por instrumentos técnicos, legais e políticos que busquem o equilíbrio entre crescimento econômico, qualidade de vida da população e qualidade ambiental.

Palavras-chave: Crescimento portuário, impactos socioambiental, Rio Grande

@- Corresponding author

1 - Universidade Federal do Rio Grande, Instituto de Oceanografia, Programa de Pós-graduação em Gerenciamento Costeiro, Av. Itália Km 8, Rio Grande, Rio Grande do Sul, Brasil. e-mails: Oliveira: ocnelaschuster@gmail.com; Domingues: mavidlrd@terra.com.br; Asmus: docasmus@furg.br; Abdallah: patrizia. abdallah@gmail.com 


\section{ABSTRACT}

Coastal municipalities have a range of land use conflicts on its territory, and the presence of a harbor significantly increases the complexity of such conflicts. To get a better understanding of the challenges involved in coastal management is necessary to take a systemic approach of the evolution of development processes and its consequences for urban structures. Territorial planning and resource management are not easy tasks in coastal municipalities. On one hand there are local pressures related to settlement invasions of environmental protected areas, growing deficit in infrastructure, and unemployment caused by national and global economic instability. On the other hand, there are political and economic pressures from induced by state and federal macro-projects development. The purpose of this article is to understand the relations between port expansion, regional growth and the environmental changes caused by that, highlighting new challenges and opportunities for coastal management. The municipality of Rio Grande (State of Rio Grande do Sul, Brazil) was taken as a case study for a systemic analysis of this process. The phases of port expansion were identified from data on cargo handling and related with development indicators. Environmental changes were evaluated by looking the urban expansion with GIS methods, comparing the years of 1975 and 2009. Improvements in urban infrastructure were consolidated only in periods in which federal investments were present, characterized as exogenous growth cycles. The observed development process significantly jeopardized coastal environmental like beach ridges and coastal fields. The process analysis highlighted that local stakeholders are not able to truly manage the environmental and social impacts generated by the macro-projects implementation. This fact is intensified by the strong pressure exerted by the private sector (e.g. industry, real estate development), and contribute to constrain a desired good application of policies and management tools. Case study conclusions suggest a needed alternative for the present rapid economic growth with impacts on the population and loss of environmental sustainability. Such alternative can possibly propose a growth pattern supported by technical, legal and policy tools that seeks a balance between economic growth, quality of life and environmental health.

Keywords: Port expansion, coastal management, Rio Grande.

\section{INTRODUÇÁO}

Os municípios costeiros apresentam uma gama de conflitos de uso de seu território, e a presença de um porto com movimentação considerável aumenta a complexidade destes conflitos. $\mathrm{O}$ desenvolvimento portuário não se dá de forma contínua e linear, gerando ciclos mais ou menos definidos os quais agravam os impactos sócio-ambientais nos períodos de crescimento acelerados. Para que se tenha um melhor entendimento dos desafios da gestão costeira tornase necessário uma visão sistêmica da evoluçáo do processo de expansão dos portos e suas conseqüências na urbe, e assim gerar subsídios para políticas ambientais locais.

A presença de ecossistemas com grande produtividade e diversidade, além da beleza cênica ímpar faz com que a zona costeira seja uma área de grande atrativo. Como conseqüência torna-se alvo dos mais variados interesses, como por exemplo, comercial, turístico e industrial, fazendo com que seus conflitos sejam cada vez mais complexos. Assim, este espaço geográfico transforma-se no palco de uma série de impactos e relaçôes que devem ser geridos de forma sustentável para que se obtenha o desenvolvimento econômico, sem perder a qualidade ambiental ou aumentar a desigualdade social.

O litoral brasileiro constitui-se em um perene desafio à gestão em fase da diversidade de situaçóes existentes neste território. São mais aproximadamente 300 municípios defrontantes com o mar. E é nesse cenário dinâmico e de alta mobilidade, tanto física quanto socioeconômica, que residem aproximadamente $18 \%$ da população do país, sendo que 16 das 28 regióes metropolitanas encontram-se no litoral (Nicolodi e Petermann, 2010). Adicionalmente, regimes de propriedade e interesses governamentais variados contribuem para que a zona costeira agregue inúmeros conflitos, envolvendo os diversos atores sociais que atuam nessa região. As crescentes e múltiplas pressóes exercidas pelo desenvolvimento sobre o litoral, e o seu paradigma de constante crescimento econômico, demandam estratégias integradas de planejamento e gestão para enfrentar os urgentes problemas ecológicos e socioeconômicos que são complexos e inter-relacionados (Arenas-Granados, 2011).

Para encontrar um equilíbrio de usos nos municípios costeiros é necessário o planejamento e a capacitaçáo de pessoas para que atenda os interesses econômicos e ambientais de forma homogênea para o não comprometimento se sua sustentabilidade ambiental urbana. Possibilitado por açóes pré-ativas como: proteção, prevenção, monitoramento e manejo de áreas prioritárias, tendo uma visão da totalidade dos processos ambientais gerando um escopo às iniciativas técnicas de planejamento que buscam a sustentabilidade e o bem-estar social (Oliveira et al, 2012).

Em municípios costeiros portuários o planejamento de usos do seu território e recursos não é uma tarefa nada fácil. Por um lado, enfrentam as pressóes de âmbito local, como invasōes de áreas de preservação ambiental, déficit crescente na infraestrutura, principalmente de saneamento básico e habitação, desemprego e subemprego causados pela instabilidade econômica nacional e mundial e pela sazonalidade característica do turismo de veraneio, entre outras. Por outro lado, enfrentam pressóes políticoeconômicas da esfera estadual e federal induzidas pelos macroprojetos de desenvolvimento.

Um aspecto a destacar com relação à implantação dos grandes projetos de desenvolvimento refere-se ao surgimento de inúmeros núcleos residenciais espontâneos no entorno da área dos projetos e/ou no entorno dos núcleos residenciais pré-existentes. Tais núcleos espontâneos refletem o crescimento desordenado das populaçóes locais devido ao intenso afluxo de migrantes que vieram de outras áreas em busca de emprego nestes grandes empreendimentos. A consequência desses processos é o surgimento de um número considerável de desempregados, tanto de migrantes como da população local, que passam a disputar e, portanto, pressionar, o mercado local de trabalho. O resultado é a 
favelização, a marginalização, a mendicância, a prostituição e a criminalidade (Domingues, 1995).

O Porto do Rio Grande, localizado no extremo sul do Rio Grande do Sul, sendo último porto marítimo brasileiro no Attântico sul, assume importância geográfica e econômica na integração dos países do sul da América Latina. A política de desenvolvimento brasileira, na tentativa de diminuir as disparidades/desigualdades do território nacional projetou pontos estratégicos no seu território para atingir suas metas, definindo como um destes pontos estratégicos o município do Rio Grande, com seu porto marítimo (Domingues, Idem). O Porto do Rio Grande recebeu um grande volume de investimentos em dois momentos distintos ao longo das últimas quatro décadas. E assim, Rio Grande, que tem sua gênese fortemente ligada ao porto, passou a absorver os reflexos deste crescimento portuário.

O objetivo deste artigo é correlacionar o crescimento portuário com o desenvolvimento municipal e com as alteraçóes socioambiental por ele causado, evidenciando novas demandas de gestáo costeira. O município de Rio Grande (RS, Brasil) foi utilizado como estudo de caso em uma análise sistêmica desse processo.

\section{MATERIAIS E MÉTODOS}

Para a análise do processo evolutivo do desenvolvimento urbano/industrial do município do Rio Grande foi feita uma revisão bibliográfica de caráter histórico com o intuito de entender as relaçóes sociais envolvidas. A partir da compilação de dados da movimentação de carga via porto, obtidos dos Boletins estatísticos das Autoridades Portuárias (ANTAQ e SUPRG), identificou-se as fases de crescimento portuário. Em seguida as fases de crescimento portuário foram correlacionadas com os indicadores de desenvolvimento municipal, onde os selecionados foram: Censo demográfico (referente à população residente), PIB (Produto Interno Bruto) municipal geral (não desmembrado por setores), IDH (Índice de Desenvolvimento Humano) municipal (não desmembrado nas três variáveis que o constituem), disponíveis na página eletrônica do IBGE (Instituto Brasileiro de Geografia e Estatística); e o número de economias atendidas com o serviço de luz, água e esgoto fornecidos pelas empresas responsáveis pelo respectivo serviço (CEEE - Companhia Estadual de Energia Elétrica e CORSAN - Companhia Riograndese de Saneamento respectivamante). De posse destes dados foi possível projetar um linha do tempo com os principais momentos econômicos e seus reflexos na população local.

A estimativa de crescimento dos indicadores de desenvolvimento, assim como para o crescimento da movimentação de carga do Porto do Rio Grande, foi feita através da formula:

$$
\left(\begin{array}{cc}
X & \text { final } \\
x & \text { inicial }
\end{array}\right) 1 / n-1 * 100 \%
$$

onde o $\mathrm{X}_{\text {final }}$ representa o valor do indicador no último ano do intervalo; $\mathrm{X}_{\text {inicial }}$ representa o valor do indicador no primeiro ano do intervalo; e $n$ representa o número de anos do intervalo.
A alteração das unidades físico-naturais foi feita através de um SIG (Sistema de Informação Geográfica) do mapeamento da expansão urbana em fotos aéreas de 1975 e imagem de satélite de 2009. O SIG do mapeamento da regiāo foi feito no programa ArcGis versão 9.2.

\section{RESULTADOS E DISCUSSÓES}

O Porto do Rio Grande foi considerado como um ponto estratégico pelo governo federal desde a década de setenta. Em virtude disso, o porto, recebeu fortes investimentos em dois momentos distintos, caracterizados como ciclos de crescimento exógeno. $\mathrm{O}$ primeiro ciclo, na década de setenta, teve a implantação do complexo Industrial-Portuário Superporto e Distrito Industrial, na tentativa da criaçáo de um corredor de exportaçáo para competir com os Países de influência do Rio da Prata. E o segundo ciclo, a partir do ano 2005, ainda incipiente no município, com a implantação do Polo Naval e offshore, na tentativa de descentralização da industrial naval brasileira.

O período compreendido entre o primeiro ciclo e o segundo foi caracterizado como uma fase de estagnação, onde não houve crescimento na movimentação de cargas transportadas via porto. Este momento de estagnação foi agravado pela queda do crescimento econômico brasileiro na década de oitenta, a chamada década perdida, além da quebra do setor industrial e pesqueiro no município.

\subsection{Desenvolvimento Municipal}

A atividade portuária exerce um significativo impacto no que se refere à arrecadação de tributos nos seus vários âmbitos, municipais, estaduais e federais, os quais inferem diretamente na construção do montante do PIB local (Alves, 2004).

Os valores arrecadados com tributos Federais, Estaduais e Municipais são utilizados na forma de investimentos, os quais exercem fundamental importância para construçáo de melhorias que beneficiam a populaçáo como um todo, principalmente no que se refere a investimentos sociais. Assim podemos fazer uma correlação entre a variação da movimentação de cargas do Porto do Rio Grande e o Produto Interno Bruto (PIB) do município, a fim de identificar se o retorno econômico, produzido pelo porto, traz recursos financeiros para a melhoria da qualidade de vida da população residente.

No primeiro ciclo exógeno, período que compreende os anos entre 1970 e 1980, constatou-se a dependência direta do PIB com a movimentação de carga, caracterizando a economia municipal fortemente vinculada ao porto e indústria pesqueira. No período de estagnação, período compreendido pelas décadas de 80 e 90 verificou-se um crescimento baixo na movimentação de carga no porto, enquanto o PIB apresentou um decrescimento alto, influenciado pela redução de empregos após a regulamentaçáo da chamada Lei de Modernização dos Portos, quebra da indústria pesqueira, e a crise internacional, caracterizando a queda do setor industrial no município.

Após o primeiro ciclo de desenvolvimento exógeno, o PIB municipal apresenta reflexos amplificados em relação à variação da movimentação de cargas no porto. $\mathrm{Na}$ fase de 
estagnação portuária, onde o aumento da movimentação de cargas é insignificante, o PIB municipal apresenta um decréscimo que foi atribuído ao declínio da indústria pesqueira que gerou alta taxa de desemprego, oscilaçóes no desempenho da Refinaria Ipiranga e o fechamento de duas plantas de fertilizantes. Na década seguinte, entre os anos de 1990 e 2000, mesmo com o começo da reação das atividades portuárias, o PIB municipal apresentou o maior declínio de todo o período analisado, trazendo os reflexos da estagnação portuária nos outros setores econômicos do município.

No segundo ciclo exógeno, entre os anos de 2000 e 2010, a similaridade de crescimento desaparece. Esta diferenciação entre o crescimento da movimentação de carga pelo Porto e o crescimento do PIB municipal no último período foi associado ao aumento do recolhimento do ICMS por parte do Governo Estadual e à expansão dos setores terciários, quaternário e quinário.

Os primeiros indicadores de desenvolvimento analisados foram o abastecimento de água tratada e a coleta de esgoto. Os quais são apresentados em número de economias, referindo-se as habitaçóes atendidas pela empresa. Estes foram analisados juntos, por sua administração pertencer à mesma companhia, Companhia Riograndese de Saneamento (CORSAN). Mesmo que o período temporal do presente artigo seja entre os anos 1970 e 2010, a análise dos dados sobre estes indicadores foi feita a partir da década de 80 em função da Companhia ter assumido este serviço nesta década.

A análise dos dados, no período que compreende os anos de 1980 e 1990, sobre a taxa de crescimento médio do serviço de coleta de esgoto no município observou-se um crescimento de $29 \%$ no número de economias atendidas (de 10.725 economias para 13.861 economias) e $164 \%$ (de 16.070 economias para 42.500 economias) número de economias atendidas com o serviço de abastecimento de água pela empresa. Este crescimento está relacionado com a grande oferta de loteamentos residenciais, por parte do Estado e iniciativa privada, além do Plano Nacional de Saneamento (PLANASA) formulado pelo Estado. No final dos anos 70 e início dos anos 80, foram ofertados alguns loteamentos providos de infraestrutura básica: Parque Marinha do Brasil, Condomínio Waldemar Duarte, Bairro Jardim do Sol, além de conjuntos residenciais tipo $\mathrm{COHAB}$ localizados na área de ocupação intensiva (Martins, 2006).

$\mathrm{Na}$ década seguinte, entre 1990 e 2000, o crescimento no número de economias atendidas pelo serviço de coleta de esgoto atingiu índices menores, tendo taxa de crescimento médio de $24 \%$ (de 13.861 economias para 17.166 economias) e de $16 \%$ (de 42.500 economias para 49.161 economias) para o serviço de abastecimento de água, decréscimo este associado à queda do setor industrial que começava a se registrar na cidade, além do fechamento do Banco Nacional de Habitação (BNH) criado pelo governo militar (Martins, Idem). No último período analisado, compreendendo os anos de 2000 e 2010 , o percentual foi menor ainda, ficando em 10\% (de 17.166 economias para 18.967 economias) para o serviço de coleta de esgoto e de 18\% (de 49.161 economias para 57.797 economias) no serviço de abastecimento de água. Com isso, fica visível que a melhoria da infraestrutura urbana no município do Rio
Grande está fortemente vinculada aos investimentos feitos pela esfera federale, nos anos isentos destes investimentos, poucas obras são realizadas pelo poder público local.

Em relaçáo aos dados do serviço de fornecimento de luz não foi possível fazer uma caracterização de todo o período temporal analisado pelo presente artigo. Isso ocorreu em função da CEEE (Companhia Estadual de Energia Elétrica) ser uma companhia mista na qual não existia um sistema de controle do número de economia atendida antes dos anos 2000. Na última década, compreendida entre os anos de 2000 e 2010, houve um crescimento médio de 26\% (de 80.092 economias para 63.475 economias) no serviço de fornecimento de luz. O qual apresentou o maior crescimento, quando comparado com o crescimento do atendimento de água e esgoto nesta década.

$\mathrm{O}$ último indicador de desenvolvimento analisado diz respeito aos IDH- Índice de Desenvolvimento Humano. No presente artigo foi utilizado o indicador geral do IDH municipal, sem fazer referencia aos seus subíndices. Isso justifica-se pelo fato que o período temporal aqui analisado é considerávelmente grande, isso dificultou a obtenção deste subíndices para as primeiras décadas em foco.

Para o município do Rio Grande, os dados fornecidos pelo IBGE mostram que o desenvolvimento humano nas últimas quatro décadas manteve-se no intervalo de classificação médio, com taxa de crescimento pouco significativo entre as décadas. $\mathrm{O}$ primeiro intervalo analisado, que compreende os anos de 1970 e 1980, foi o período de maior crescimento deste indicador, com taxa de $2,67 \%$ (de 0,56 para 0,729 ).

Destaca-se que entre os anos de 1970 e 1980, o município do Rio Grande foi o que apresentou a mais alta taxa de crescimento industrial do Estado, tendo a sua participação no valor da produção industrial gaúcha quase dobrada neste período, passando de 3,42\% para 6,63\% (Domingues, 1995 ). No entanto, segundo Domingues (1995) estes números promissores da atividade industrial do município não refletiram numa melhoria das condiçóes de vida da maioria da população local; ao contrário, estes dados confirmam o caráter concentrador de renda e, portanto, o caráter excludente do ponto de vista sócio-econômico-espacial de largas parcelas das populaçóes comuns a todos os lugares/ regióes onde estes grandes projetos de "desenvolvimento" foram/são implantados.

Nas décadas seguintes, entre os anos de 1980 e 2000, a taxa de crescimento médio do IDH municipal foi pouco significativa, apresentando-se em $0,136 \%$ (de 0,729 para 0,739 ) e $0,707 \%$ (de 0,739 para 0,793 ) respectivamente. Para o último intervalo analisado, que compreende os anos de 2000 e 2010, não é possível calcular o crescimento médio em função da não liberação de dado sobre IDH no ano de 2010 pelo IBGE. Os dados analisados acima são apresentados na figura 1.

Podemos fazer uma comparação entre o crescimento médio da população riograndina e o crescimento médio do IDH municipal. Na figura 2 temos as taxas de crescimento médio das duas variáveis, mostrando que apenas no primeiro intervalo o desenvolvimento humano municipal acompanhou o crescimento demográfico. Esta década representou o período de maiores investimentos econômicos em Rio Grande, que atraiu grande contingente 


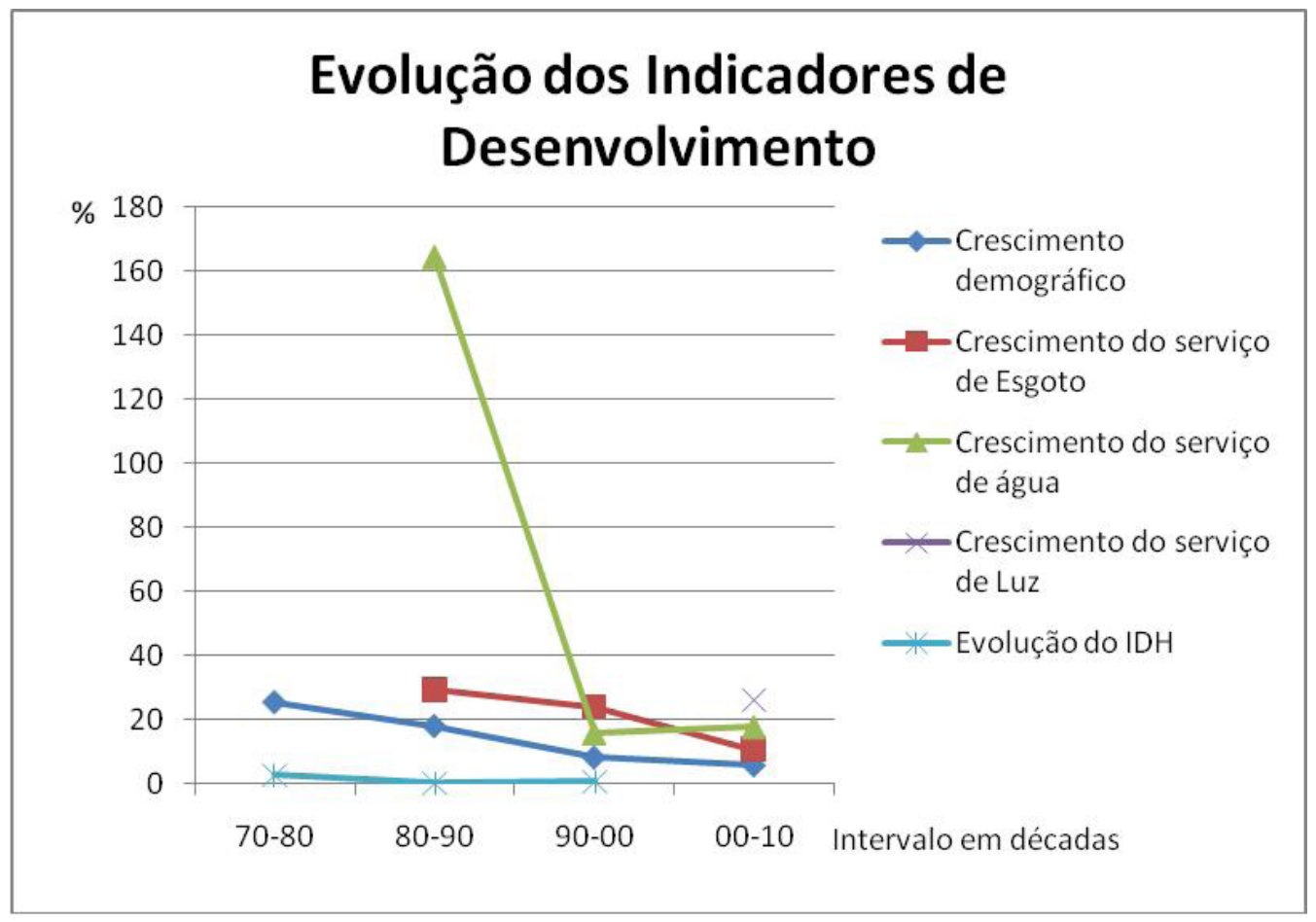

Figura 1. Crescimento médio do serviço de água, esgoto, luz, IDH e da População Riograndina. Figure 1. Average growth of water, sewage, electricity, IDH and Population Riograndina.

populacional e gerando maior renda para a cidade, havendo, consequentemente, o crescimento no IDH. Mas isso não significando melhoria na qualidade de vida da população, principalmente, nas classes de baixa renda.

Na década seguinte, entre os anos de 1980 e 1990, a população continua crescendo, ainda como reflexo dos projetos industriais implantados na cidade na década anterior. Mas, muito dos investimentos deste período anterior são cessados e a qualidade de vida da população declina, surgindo áreas ocupadas irregularmente, pela população de baixa renda, estas sem acesso aos benefícios sociais, como escolaridade, fazendo com que o IDH não acompanhasse este crescimento populacional. No último período que pode ser comparado, temos uma melhoria no crescimento do IDH, mas ficando baixo do crescimento da população riograndina.

\subsection{Alteração Ambiental}

A base física do município de Rio Grande abrange depósitos sedimentares resultantes da interação entre ambientes marinhos, transicionais e continentais. As feições geomorfológicas atuais são reflexos dos processos genéticos que atuaram na instalação desses ambientes, fundamentalmente associados às variaçóes relativas do nível do mar desde o Terciário até o Recente (Tagliani, 1997). Os depósitos pleistocênicos em Rio Grande ocupam porçóes topograficamente mais elevadas do que os mais recentes, constituídos por sedimentos lagunares, eólicos e marinhos. Os depósitos holocênicos, também representados por sedimentos lagunares, eólicos e marinhos, distribuem-se por grandes áreas adjacentes aos corpos lagunares e ao mar. Com exceção de algumas regióes das dunas, estas deposiçôes recentes constituem áreas planas, baixas, alagáveis e sítio das maiores aglomeraçóes populares do município (Tagliani, Idem).

A vegetação presente nestas áreas é classificada segundo o Instituto Brasileiro de Geografia e Estatística, disponível na página eletrônica, como "Áreas de Formaçóes Pioneiras" na planície costeira sul-rio-grandense, subdividindo-a em 2 categorias: 1) Áreas de influência marinha, que recobrem a maior parte dos depósitos eólicos (dunas fixas e vivas), areias e depósitos síltico - argilosos, ricos em matéria orgânica, depositados próximos à linha de costa em planícies de maré e feixes de restinga; 2) Áreas de influência fluvial, situadas em torno das margens da Lagoa Mirim, maior parte das margens da Lagoa dos Patos e margem oeste da Lagoa Mangueira.

Assim, a comparação do mosaico das unidades físico naturais - unidades com homogeneidade interna em relação a processos físicos ativos e relacionados à vegetação natural - presentes na regiáo com os mapas da expansão urbana do município do Rio Grande nos anos de 1975 (início do $1^{\circ}$ ciclo exógeno) e 2009 (primeiros anos do 20 ciclo exógeno) constata-se a supressão dos ambientes de marisma e cristas de praias litorâneas (CPlit) com campos litorâneos, CPlit com mata de restinga, CPlit com plantação de eucalipto, CPlit com vegetação de banhado, Planície marinha elevada (PME) com campos litorâneos e Dunas obliquas com campos litorâneos (Figura 3). A evolução da expansão urbana obtida pelos mapas de expansão urbana nos anos de 1975 e 2009 mostra um crescimento bipolar. No qual o crescimento da cidade se dá nos eixos rodoviário Rio Grande/Pelotas (BR 392) e Rio Grande/ Balneário Cassino (ERS 734), indicando uma futura supressão das unidades físico naturais dos tipos: 


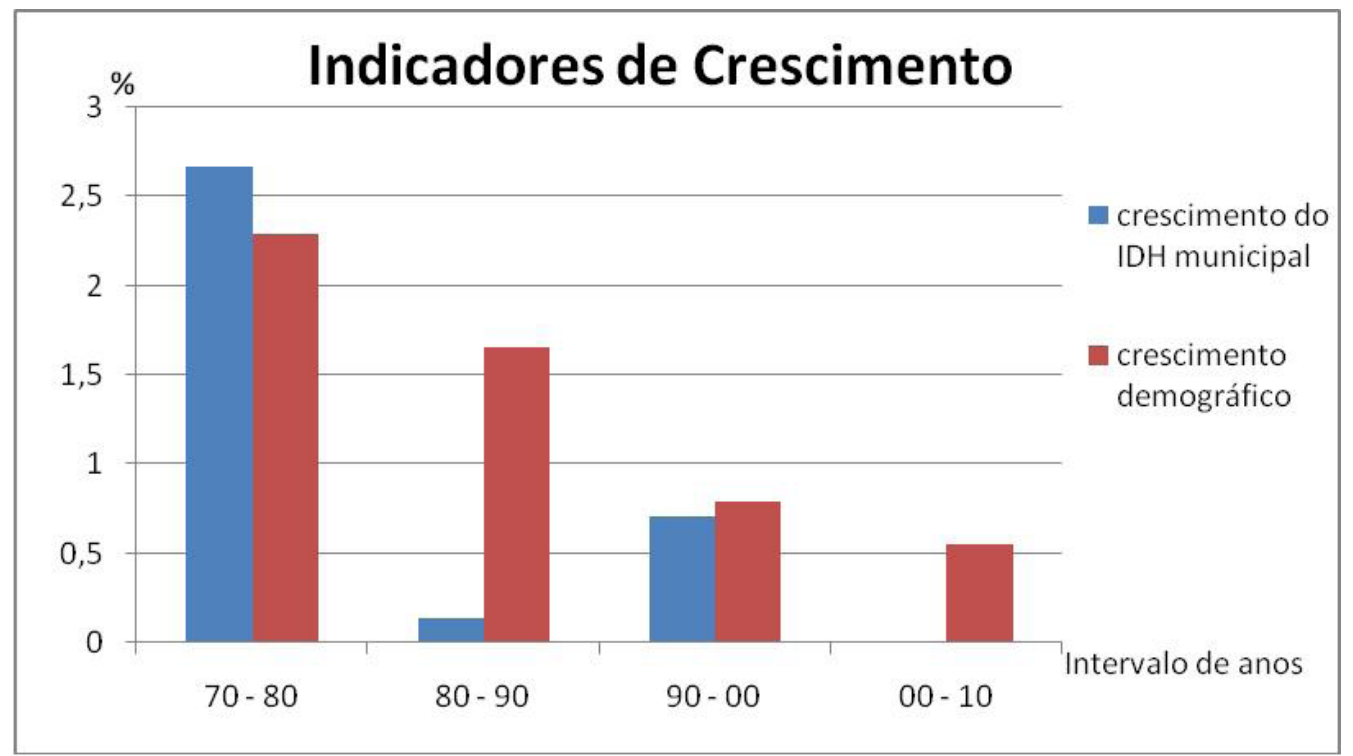

Figura 2. Comparação entre o crescimento médio do IDH e o demográfico em Rio Grande.

Figure 2. Comparison between the average growth of IDH and demographic Rio Grande.

CPlit com matas de restinga, planície lagunar inundável (PLA) com mata de restinga, PLA com campos litorâneos, PLA com vegetação de banhado, PLA com marismas e PLA com plantação de eucalipto.

O município de Rio Grande apresenta uma grande variedade de formaçóes vegetais de importância ambiental e socioeconômica, as quais vêm sofrendo conflitos e problemas ambientais mais evidentes. Por sua ocupação urbana ser margeada de ambientes frágeis as intervençóes antrópicas tem conseqüências diretas sobre estes ecossistemas. Como por exemplo, mudanças no canal de desembocadura do estuário, ocupado pelo Porto, pode induzir mudanças na circulação e na salinidade, que por sua vez geram perda de biodiversidade no ambiente estuarino. E essa perda de biodiversidade pode se converter em problemas econômicos para os pescadores artesanais que sobrevivem do estuário, além de problemas sociais como a degradação da beleza cênica destes ambientes.

Dentro desta problemática da gestão costeira, vários fatores contribuem para o agravamento dos conflitos de uso e ocupação do espaço, principalmente em municípios que exercem a função portuária como é o caso de Rio Grande. Em portos onde a atividade econômica é consideravelmente elevada e a estrutura e a dinâmica possuem alto grau de complexidade, os impactos/conflitos gerados podem afetar tanto os ecossistemas adjacentes como também o modo de vida da populaçáo. Necessitando assim, um planejamento sistêmico e de longo prazo para absorver, de maneira sustentável, a convergência de energia (produtos, investimentos econômicos, tecnologias, informaçóes, pessoas, etc) em momentos de expansão.

Podemos visualizar os processos atuantes no município como um sistema, onde a fonte de energia/investimentos externa refere-se ao Governo federal e setor privado, a fonte de energia/investimentos interno refere-se ao poder público local e atores locais, e no interior do sistema estão as interações com a maior ou menor entrada de energia/investimentos e saída referente às mercadorias, serviços e energia que saem pelo porto. Assim, para a década de 70 onde se tem a entrada de investimentos por parte do Governo federal que geram crescimento econômico para o município. Para a década de 80 , onde não há investimentos externos gerando estagnação e/ou queda no crescimento econômico. E no terceiro e último período está representado à década de 2000, onde temos novamente há entrada de investimentos externos gerando crescimento econômico para o município do Rio Grande.

Esta visão sistêmica do processo evolutivo do município do Rio Grande mostra de maneira clara que a queda do crescimento econômico na década de 80 tem forte ligação com a baixa capacidade de articulação dos atores locais, intensificada pela falta de recursos, falta de capacitação dos servidores, salários baixos e descontinuidade política, que geram grandes perdas no sistema. Para o momento atual, onde, se por um lado, tem-se a retomada do crescimento das exportaçóes e da atividade industrial via porto, e de outro, tem-se a permanência da falta de quadros técnicos qualificados e bem remunerados, fica o grande desafio do enfrentamento no curtíssimo prazo das demandas infraestruturais urbanas que darão suporte a este novo processo de apropriação técnoprodutiva do território, mesmo já tendo uma melhora da capacidade de governança entre a gestão pública municipal, o porto e as empresas.

Cabe destacar que apesar de algum diálogo interinstitucional (secretarias, empresas e porto), não se observa uma integração entre os instrumentos de gestáo sob tutela das diferentes instituiçôes, ou seja, entre o Plano Diretor Municipal, o Plano Ambiental Municipal (PLAM), o Zoneamento Ecológico-Econômico do Município (ZEEM), o Plano de Desenvolvimento e Zoneamento do 


\section{Expansão Urbana de Rio Grande (1975 - 2009)}

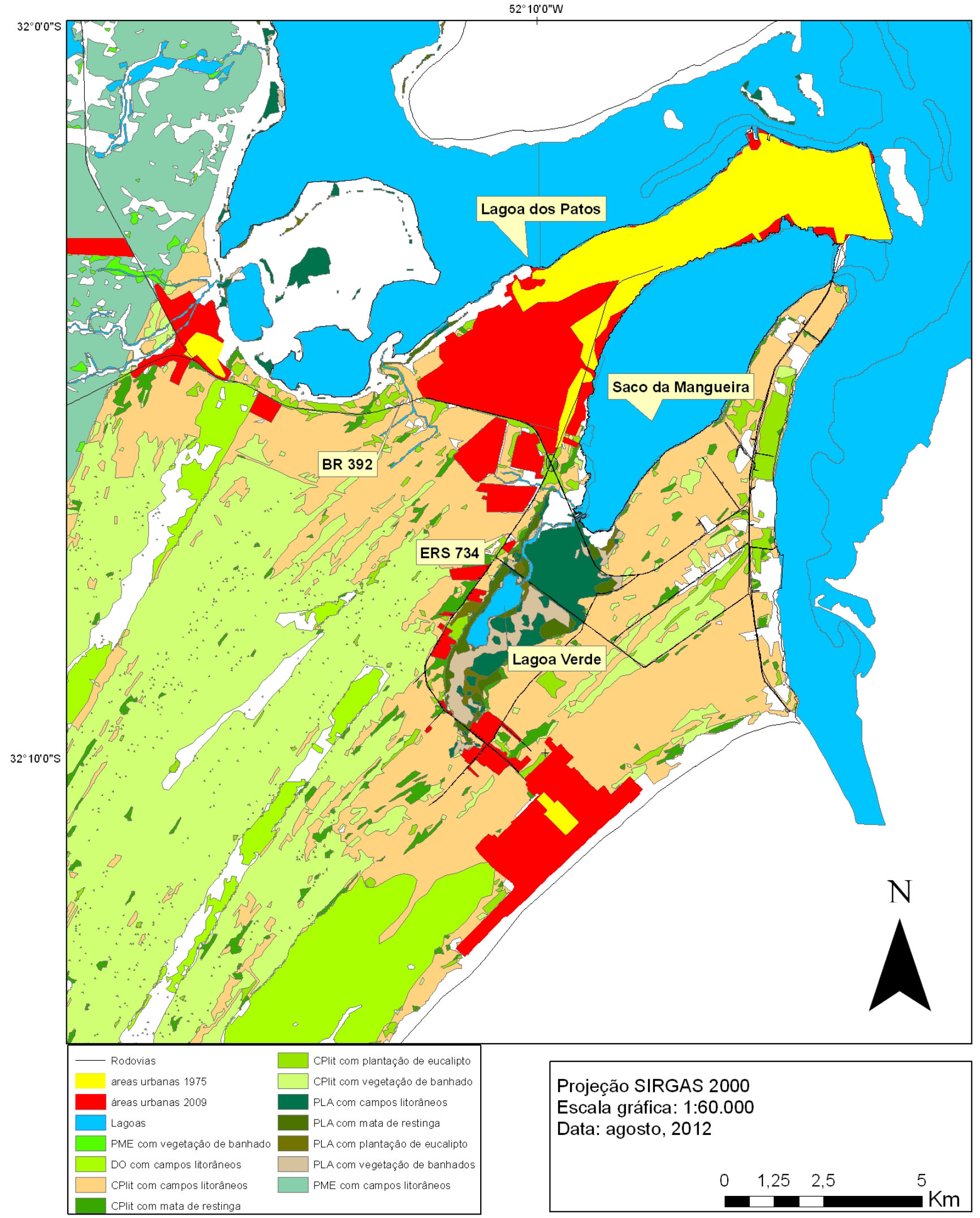

Figura 3. Mapa com a alteração dos ecossistemas em Rio Grande. Elaborado por Tagliani (2002) e adaptado por Daniela Oliveira. Figure 3. Map with change of ecosystems in Rio Grande. Prepared by Tagliani (2002) and adapted by Daniela Oliveira. 
Porto Organizado do Rio Grande (PDZ) e o Plano Diretor do Distrito Industrial. Dentre eles apenas o Plano Diretor Municipal foi implantado formalmente, enquanto que os outros instrumentos não passaram da fase de elaboraçẫo.

A falta de articulação e/ou compatibilização entre as diversas políticas/instrumentos incidentes sobre a Zona Costeira no âmbito local leva, muitas vezes, conforme Tagliani e Asmus (2011), a uma visão setorizada da realidade, pois cada setor tende a destacar a sua visão fazendo com que isto prejudique e/ou comprometa as açóes voltadas para uma gestâo integrada. Ao nível local esta gestão tem tido um caráter setorial, com processos decisórios fragmentados e reativos, e com foco nos sintomas e não nas causas em si. Tal caráter tem denotado uma necessidade de coordenação e manejo pró-ativos, através de um processo de gestão que integre os elementos e processos sócio-ambientais do ecossistema costeiro a essa importante região. Assim a visão sistêmica de todo o complexo estuarino se mostra de fundamental importância no planejamento da ocupação destes ambientes tão sensíveis a estas mudanças. Pois esta visão sistêmica permite a integração e harmonização dos setores, mostrando a totalidade dos processos no espaço planejado.

O mesmo foi evidenciado por Asmus et al (2006) quando considerada a questão política relativa à implementação do Plano Nacional de Gerenciamento Costeiro, constatamse obstáculos políticos em todos os níveis, principalmente nos municipais, aonde prefeitos e vereadores normalmente chegam ao poder através do apoio de alguns segmentos econômicos que na maioria das vezes não estão preocupados com um desenvolvimento sustentado para o município e sim aferir maiores lucros dentro das suas áreas de atuação.

Em uma análise feita por Asmus et al (2006) nos municípios costeiros do litoral norte do Estado do Rio Grande do Sul, observa-se, como conseqüência, a construçáo de Planos Diretores altamente liberais quanto à ocupação de solo para edificaçóes. Em alguns casos, tais planos permitem o estabelecimento de altíssimas densidades populacionais, não havendo a preocupação com a implantação de sistemas de tratamento de esgotos e resíduos e com a ocupação de áreas ambientalmente frágeis e de preservação. No caso de Rio Grande isso fica evidenciado pelas modificaçóes feitas no Plano Diretor Municipal, que teve a redução de 50 para 30 metros da área de proteção permanente das margens dos arroios, além da alteração de uma área que anteriormente era classificada como área de proteçáo ambiental para área de interesse social, que permitiu a construção de um condomínio residencial.

Desta maneira o município de Rio Grande tem um grande desafio a enfrentar, com a vinda de investimentos econômicos, tanto na área portuária como na área urbana, que vem atraindo intensos fluxos migratórios para o município. Isto exigirá do poder público um adequado planejamento do seu território para evitar potenciais conflitos de uso do espaço, como a rápida expansáo urbana e a conseqüente favelização, o colapso ou saturação das infraestruturas, além do deficiente sistema de drenagem urbana, sem perder de vista a degradação ambiental eminente.

Caberá ao poder público local saber lidar com as fortes pressóes do setor privado, industrial e imobiliário, na ocupação de seu território. Porque, ou se assegura a aplicação das leis ambientais para se ter o desenvolvimento sustentável, mantendo-se o equilíbrio entre o crescimento econômico, qualidade de vida da população e a qualidade ambiental. Ou se obtêm um crescimento econômico rápido, em curto prazo, com futuros constrangimentos para a população e com perda da sustentabilidade ambiental.

\section{CONCLUSÓES}

Países com proporçôes continentais similares ao Brasil que fazem grandes investimentos econômicos em pontos estratégicos para alavancar seu desenvolvimento devem ter seu planejamento alçados no tripé econômico, social e ambiental. O rápido crescimento econômico nos municípios gera pressóes diversas na urbe e no meio ambiente, sendo imprecindível o entendimento do processo evolutivo e uma visão da totalidade dos processos para se buscar de forma conjunta a sustentabilidade ambiental e o bem-estar social.

Para que não se tenha a repetição da estagnação econômica e alteração fisico natural pós primeiro ciclo de crescimento exógeno torna-se necessário a articulação dos atores locais para sustentarem o desenvolvimento municipal. A pouca articulação existente entre os órgãos ambientais e outros setores da administração pública, além das descontinuidades políticas em todas as esferas, comprometem o crescimento econômico e a melhora na qualidade de vida da população.

Existem exemplos das consequências geradas pela implantação de macroprojetos, induzidos pela esfera federal, nos municípios costeiros de pequeno e médio porte, como por exemplo em Macaé no Estado do Rio de Janeiro. Estes exigem uma boa articulação entre as instituiçôes e uma capacidade de resposta rápida para que não haja uma degradação socioambiental em nível local. $\mathrm{O}$ cessamento abrupto de investimentos deixa a cargo do poder público local para lidar com os passivos ambientais e sociais causados pela atraçáo de um grande contingente populacional para estes municípios. Assim, traz à tona o pouco preparo dos administradores e servidores públicos no que tange à resolução destes conflitos.

\section{BIBLIOGRAFIA}

Alves, E.B. (2004) - As relaçóes entre a atividade portuária e o atual estágio de desenvolvimento do município do Rio Grande. 49p, Monografia de Graduação, Universidade Federal do Rio Grande, Rio Grande, RS, Brasil. Não publicado.

Arenas-Granados, P. (2011) - Manejo Costeiro y Sustentabilidad en Iberoamérica. 413p, Editorial Académica Espanōla. ISBN: 9783847354369. Disponível em http://www. uca.es/grupos-inv/HUM1 17/grupogial/paginas/ publicaciones/libropedrodosmildoce

Asmus, M.L.; Kitzmann, D.; Laydner, C.; Tagliani, C.R.A. (2006) - Gestão Costeira no Brasil: instrumentos, fragilidades e potencialidades. Revista de Gestão Costeira Integrada (ISSN: 1677-4841), 5:52-57, Itajaí, SC, Brasil. Disponível em http://www.praia.log.furg.br/ Publicacoes/2006/2006a.pdf

Domingues, M.V.D.L.R. (1995) - Superporto do Rio Grande: plano e realidade. Elementos para um discussāo. 312p, Dissertação de mestrado, Universidade Federal do Rio de Janeiro, Rio de Janeiro, RJ, Brasil. Não publicado. 
Martins, S. F. (2006) - Cidade do Rio Grande: industrialização e urbanidade (1873 - 1990). 234p., Editora da FURG, Rio Grande, RS, Brasil. ISBN:8575660799.

Nicolodi, J.L; Petermann, R.M. (2010) - Mudanças Climáticas e a Vulnerabilidade da Zona Costeira do Brasil: Aspectos ambientais, sociais e tecnológicos. Revista de Gestão Costeira Integrada (ISSN 1646-8872), 10:151177, Itajaí, SC, Brasil. Disponível em http://www.aprh. $\mathrm{pt} / \mathrm{rgci} /$ revista $10 \mathrm{f} 2 . \mathrm{html}$.

Oliveira, D.S.; Asmus, M.L.; Domingues, M.V.D.R. (2012) - Planejamento Urbana em Áreas Inundáveis de um Municipio Costeiro: Estudo de Caso em Rio Grande,
Rs, Brasil. Revista Costas - Revista Iberoamericana de Manejo Costeiro Integrado (INSS 2304-0963). Montevideo, Uruguay.

Tagliani, C.R.A. (1997) - Proposta para o manejo integrado da exploração de areia no municipio costeiro de Rio Grande, RS. Um enfoque sistêmico. 157p, Dissertação de Mestrado, Universidade do Vale do Rio dos Sinos, São Leopoldo, RS, Brasil. Não publicado.

Tagliani, P.R.A.; Asmus, M.L. (2011) - Manejo integrado do estuário da lagoa dos patos: uma experiência de gerenciamento costeiro no sul do Brasil. 250p, Editora da FURG, Rio Grande, RS, Brasil. ISBN: 9788575662069. 